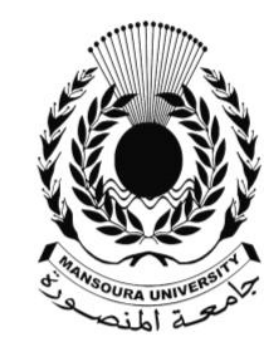

جامعة المنصـورة المانئ

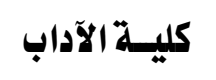

\title{
الوعي بالذات والقلق لدى عينة هن طلاب قسم علم النفس بجاهعة الطائف
}

\author{
إعـــداد \\ الدكتور/ سعد ريـاض البيومي \\ أستاذ مشارك - علم النفس الاكلينيكي \\ قسم علم النفس - كلية الآداب - جامعة الطائف.
}

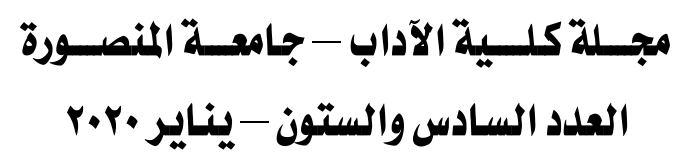




\title{
الوعي بـالذات والقالق لدى عينة مز طلاب قسلم علم النفسر بجامعة الطائف
}

\author{
د. د. سعلد رياض البيومي \\ أستاذ مشارك - - علم النفس الاكلينيكي \\ قسم علم النفس - كلية الآداب - جامعة الطائف. \\ يهذف البحث الحالي إلى التعرف على مستوى كل من الوعي بالذات والثقل لادي عينة من طلاب قسم علم النفس بجامعة الطائف،

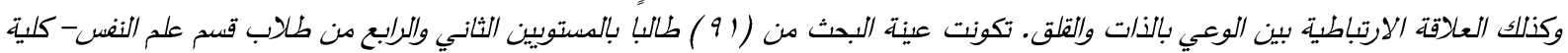 \\ الآداب. وللتحقق من صحة الفرض تم استخدام مقياس الوعي بالذات من إعداد الباحث، ومقياس "تيلور" للقلق، ترجمة وتقنين مصطفى فهمى، ولاطي، \\ وخحم أحدد غالي. \\ وأثارت النتائج إلى وجود مستوى من الوعي بالذات لدى الطلاب يتراوح بين المتوسط والمرتغع، ومستوى من القلق يتراوح بين المتوسط

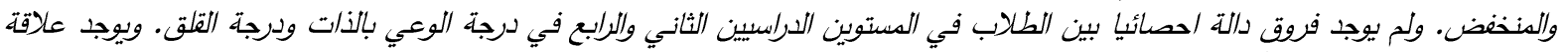

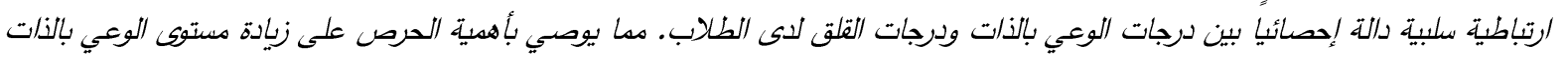 \\ حتى يتغلب الشخص على الكثير من اضطرابات الشخصية. وخاصة لدى الطلاب الذين في مرحلة التأهيل لأن يكونوا أخصائيين نفسيين. \\ الكلمات المفتاحية : الوعي بالذات - القلق - طلاب قسم علم النفس.
}

\section{Abstract}

Current research aims to identify the level of Self-awareness and anxiety for a sample of students from the Department of Psychology, Taif University. As well as the correlation between self-awareness and anxiety. The research sample consisted of (91) students at the second and fourth levels from the students of the Psychology Department- faculty of arts. Have used the scale of self-awareness to verify hypotheses, prepared by the researcher, and Taylor's anxiety scale, Translated and standardization by Mostafa Fahmy and Mohamed Ahmed Ghali.

The results indicated that there is a level of self-awareness among students ranging from medium to high, And the level of anxiety between medium and low. There were no statistically significant differences between students at the second academic level and students at the fourth academic level in the degree of self-awareness and the degree of anxiety. There is a statistically significant negative correlation between students 'degrees of self-awareness and students' degrees of anxiety. And this recommends the importance of taking care to increase the level of self-awareness so that a person can overcome many personality disorders. Especially among students who are under qualification to be a psychologist.

Keywords: Self-awareness - Anxiety - Psychology Department Students

الذات (Jack \& Smith, 2007, p.48;

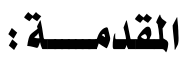
Topuz \& Arason 2014, p.641) الفرد على ادراك القيم الخاصة به وميوله (Fung, واحتياجاته ومراكز القوة والضعف لدايه 2011, p.65) والضعف وادراكه لمشاعره يؤثر على طبيعة سلوكه ويعمل على تدعيم علاقاته الإنسانية مع العاتي

تعد حياة الانسان سلسلة من الخبرات

والمهارات والممارسات يمكن أن يكون لها التأثير السلبي أو الإيجابي على سلوكه أو انفعالاته أو لون لونائ أفكاره وتشكل لديه ما يسمي الوعي بالذات.

ويشتمل الوعي بالذات على جوانب عديدة

ومترابطة منها الادرالك والمشاعر والسلوك ومراقبة بلات 
ولكن هل يكون لهذه الدراسة تأثيراً ايجابياً أم سلبياً على شخصية الطالب? وهل هذا يحقق حالة من الوعي بالذات أم يسبب قدر من القلق؟ وهل

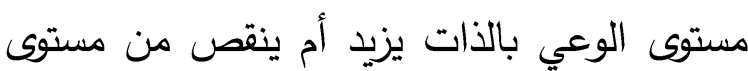

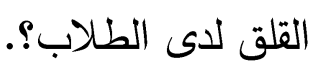

وهنا تتحدد مشكلة البحث في تحديد مستوى الوعي بالذات والقلق للاي عينة من طلاب قسم علم النفس بجامعة الطائف. وسوف يتحقق

ذلك من خلال الإجابة على التساؤلات الآتية:

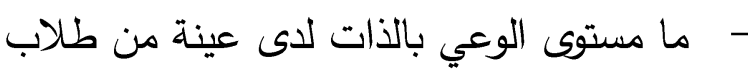
قسم علم النفس بجامعة الطائف؟

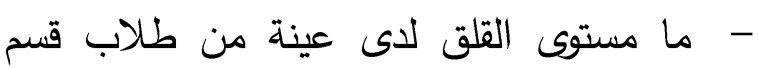
علم النفس بجامعة الطائف؟ - - هل يوجد فروق في درجة الوعي بالذات ودرجة القلق بين طلاب المستوين الثاني

$$
\text { والرابع? }
$$

- هل توجد علاقة ارتباطية بين الوعي بالذات والقلق لدى طلاب قسم علم النفس بجامعة

الطائف؟

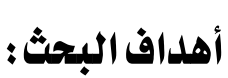

يعد الوعي بالذات من أهم مقومات الصحة

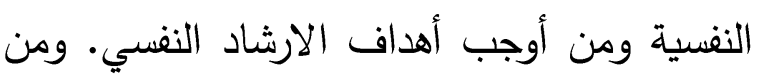

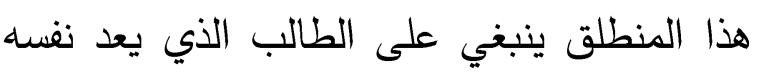
كأخصائي نفسي في المستقبل أن يفهم نغسه أولاً، ويعرف مواطن قوته وضعفه وصحته النفسية. ولذا

$$
\text { يهدف البحث الحالي إلى ما يلي: }
$$

- التعرف على مستوى الوعي بالذات والقلق لدى طلاب قسم علم النفس بجامعة الطائف.
ويكتسب الفرد الكثير من الخبرات إما من خلال المواقف الحياتية أو من الممارسات التعليمية التي تسبب له تغير في مستوى الوعي بالذات. وبالنسبة لطلاب قسم علم النفس يمكن أن لن فئس يكون لدراسة سلوك المضطربين أو المرضي أو الو الونيه المنحرفين التأثير الفعال على البعض دون الآخر،

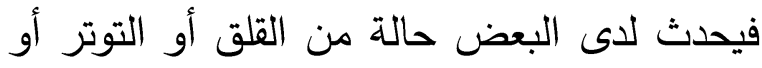

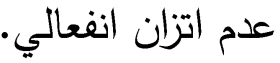
والقلق هو انفعال قوامه الخوف حيث الخعافي يتجلى في هذا العصاب المظاهر النفسية والجسمية لانفعال الخوف، ويعد حالة دائمة من لإنيان الضيق والتوجس الهائم الطليق. ومن أعراض القلق الجسمية انقباض القلب وخفقانه وفقدان

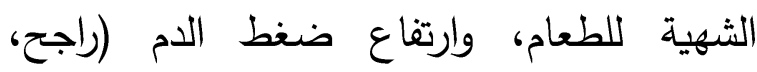
.$(09) 61999$ الخبرات والمعارف يمكن أن تؤثر في مستوى الوعي والذي بدوره يمكن أن يؤثر في مستوى القلق. ولذا ينبغي تحديد مدى تأثير لئري المعارف والدراسات النفسية على درجة الوعي

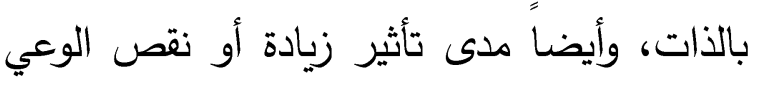
بالذات على اضطراب الثخصية أو استقرارها وخاصة القلق لاى طلاب قسم علم النفس.

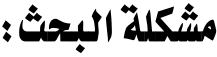

يقوم طلاب علم النفس بالدراسة العلمية لسلوك الانسان من حيث هو كائن حي يرغب ويحس وينفعل ويتذكر ويتخيل ويفكر ويعبر ويريد

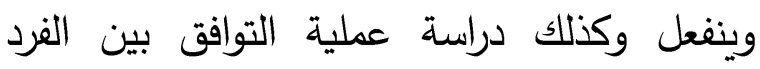

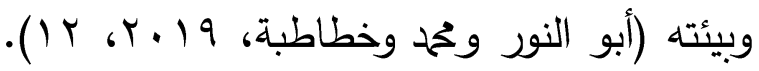


مصلحات البحث : البه

الوعي بالذات: Self-awareness.

تعريف "Warmerdam".

الوعي بالذات هو تصور الفرد الواضح

عن شخصيته بما فيها من مراكز القوة والضعف لفت

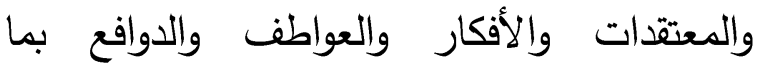
الآخرين

يساعده لهم

.(Warmerdam, 1994, p. 56)

يعرف الباحث الوعي بالذات: بأنه ادراك الفرد لأفكاره وانفعالاته وتفسيره لسلوكه وتحديد مواطن القوة والضعف في شخصيته. واجرائيا: بالدرجة التي يسجلها الطالب

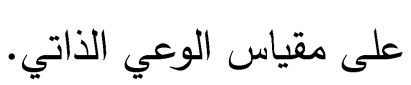

القلق: Anxiety.

تعريف "Riskind" وآخرون القلق: هو

شعور الفرد بالخوف والتوتر وإدراك متزايد بوجود تهديدات غامضة موجودة في المستقبل .(Riskind, Alloy, \& Manos, 2005) يعرف الباحث القلق: بأنه الخلل في الوعي

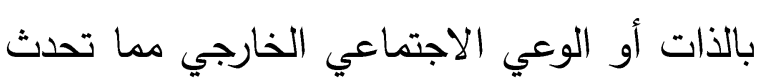

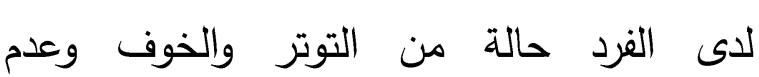
الاستقرار - - الاك

واجرائيا: بالدرجة التي يسجلها الطالب على

مقياس القلق.

الاطار النظري والدراسات السابقة:

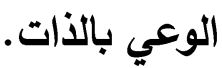

يعد موضوع الوعي بالذات من

الموضوعات الهامة في مجال علم النفس حيث أن من لوض

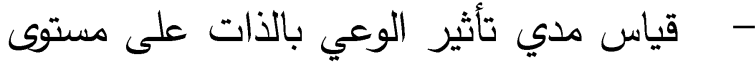
القلق لاى طلاب الجامعة.

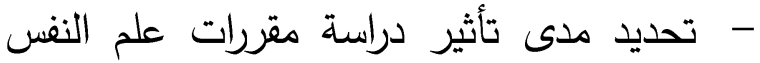
على الوعي بالذات والقلق على الطلاب.

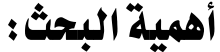

يسعى طلاب علم النفس لدراسة السلوكى

الإنساني وما يؤثر فيه. فيحدث لديهم درجة من لن درجات الوعي بالذات الانسانية من الناحية النظرية. ولكن هل ينعكس ذللك الوعي بالذات

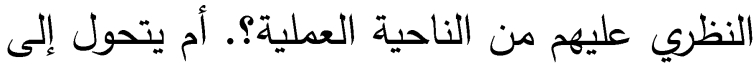
حالة من القلق الظاهري أو قلق المستقبل. وهنا تتحدد أهمية البحث فيما يلي: الأهمية النظرية: جمع تراثا نظرياً يساعد

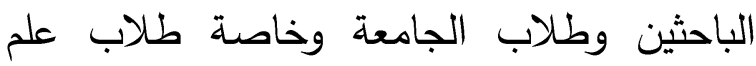
النفس على فهم طبيعة القلق ومدى ارتباطه بمستوى الوعي بالذات. وكيف يحدث القلق وما أهمية الوعي بالذات في تحديد مستوى القلق؟ وما بلات علاقة الوعي بالذات باضطرابات الشخصية وخاصة القلق.

الأهمية التطبيقية: تمثل الأهمية التطبيقية في مساعدة طلاب الجامعة على تفسير بعض الظواهر النفسية لايهم، وكذلك التغيرات السلوكية والانفعالية التي تحدث لهم. وتقديم العون للمؤسسات الجامعية، والقائمين بالإرشاد الطلابي

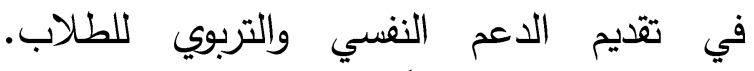
بالإضافة لتقديم مقياسا للوعي بالذات يضاف إلى لى لإن

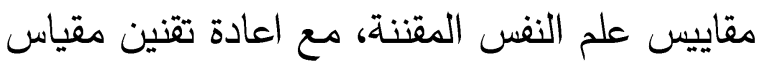
القلق بعد الضبط والتعديل. 
إعادة تشكيلها في الذاكرة (الزيات، ا. ..؟، .$(\varepsilon q)$

ولذلك فالوعي بالذات هو قدرة الفرد علي

مراقبة نفسه، والتعرف على مشاعره، ومعرفة العلاقات بين الأفكار والمشاعر والانفعالات، واتخاذ القرارات الثخصية ورصد أفعاله وتحديد عواقبها.

ومن الدراسات التي تتاولت موضوع الوعي

الذاتي دراسة (ناجي، وعزيز، 17 (ب) والتي هدفت إلى الكشف عن مدى تحقق الوعي بالذات لاى طلاب الجامعة. وأشارت النتائج إلى أن لن طلاب الجامعة يتمتعوا بدرجة من الوعي بالذات. في حين لم يوجد فروق دالة احصائيا بين طلاب الجامعة تبعا لمتغير الجنس والتخصص والمرحلة. ودراسة (الخالدي، ؟ ا.با) والتي هدفت إلى التعرف على العلاقة بين الوعي بالذات والتوافق النفسي لاى طلاب المرحلة الثانوية بمحافظة الجوف. وأشارت النتائج إلى وجود درجة من الوعي بالذات لدى طلاب المرحلة الثانوية وكذلك وجود علاقة ارتباطية دالة ايجابيا بين الوعي بالذات والتوافق النفسي.

ودراسة (Fung, 2011) والتي هدفت إلى الكثف عن العلاقة بين الوعي بالذات ودرجة قبول الفرد لذاته وعلاقته مع الآخرين. وأشارت النتائج إلى أن هناك علاقة ارتباطية دالة احصائيا بين الوعي بالذات وقبول الذات ونوعية العلاقات مع الآخرين. كما أشارت النتائج إلى أن الخبرة في الحياة الشخصية والعائلية أكثر من الخبرة في بيئة
هنالك أهمية كبيرة لفهم النفس البشرية والوعي بالذات، وتقييمها موضوعيا، وفهم الحقائق المتعلقة بقدرات الانسان واحترامه لمبدأ الفروق الفردية بين الأفراد (الزبيدي، 0 . . ب، ع). والوعي بالذات هو قدرة الفرد على توجيه

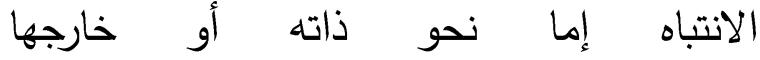
"Goleman" وعرف). (Buss,1980,p.54) الوعي بالذات بأنه معرفة الفرد لذاته وأن يكون على وعي بانفعالاته عندما تظهر ومن خلال هذه المعرفة يصبح قادرا على أن يمتلك مهارة التمثيل العاطفي (Goleman,1995, p.48). ويرى "Hippe" أن الوعي بالذات يتضمن معرفة الفرد لنقاط قوته وكذلك المناطق التي تمثل التحدي بالنسبة له والقبول بالواقع والعمل على احتمالات المستقبل (Hippe, 2004, p. 241). والفرد الواعي بذاته يتسم بقدراته على فهم حالته النفسية أثناء التعامل مع الآخرين، ويمتلك الادراك لحياته الانفعالية وادارتها بأسلوب عقلاني لكونها شخصية استقلالية واثقة من نفسها ويتمتع

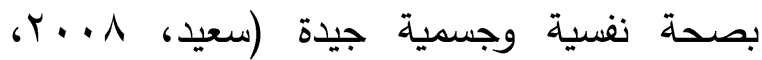
.$(11 \mathrm{~V}$

ويتوقف المدى المحدد لاستقرار الوعي بالذات لاى القرد على بعض المقومات منها فكرة الفرد المسبقة عن نفسه وعن قدارته ومعلوماته وامكاناته التي يمتلكها. ووعيه بمشاعره وأفكاره ووعيه بحجم المهام المكلف بها، ومدى صعوبة المشكلات التي تعترضه وطبيعة الضغوط والظروف التي تقابله. وهذا يعتمد على خبراته السابقة وأسلوب الوعي بهذه الخبرات والقدرة على العمل. 
والوعي بالذات من المتغيرات النفسية الهامة والتي ارتبط بالعديد من المتغيرات الأخرى

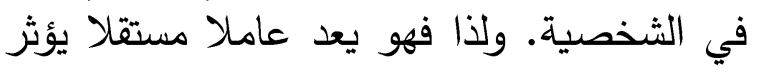
في كثير من العوامل، وفي نفس الوقت عاملت عاملا تابعا يتأثر بالعديد من الممارسات السلوكية والمعرفية والانفعالية. القلق:

القلق هو القاسم المشترك في الاضطرابات

النفسية، والقلق هو الحالة التي يشعر بها الفرد إذا تهدد أمنه أو تعرض للخطر أو لقي إهانة أو لو أولئ أحبط مسعاه أو وجد نفسه في موقف صراعي حاد لون

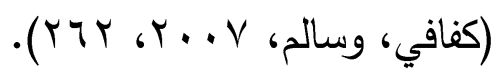
والقلق حقيقًة من حقائق الوجود الانساني ويعد جانبا ديناميا في بناء الثخصية ومتغيرا

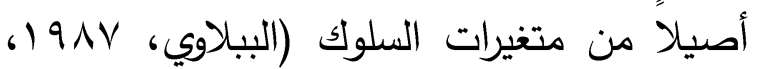

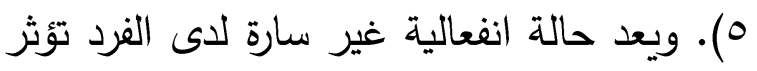
في مستوى أدائه، وعلاقاته الاجتماعية، وعلى أفعاله مدى شعوره بالطمأنينة نتيجة تعرضه لأحداث نفسية ضاغطة خلال حياته سواء أكانت هذه الأحداث واضحة لديه أم غامضه. مما يؤدي إلى تغيرات داخلية وخارجية للفرد (أبو النور وخطاطبة لإنة

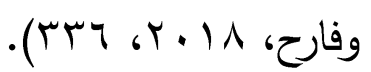
وقام "حامد زهران" بتعريف القلق بأنه حالة من التوتر الثامل والمستمر نتيجة توقع خطر فعلي أو رمزي يمكن أن يحدث ويصاحبها أسباب

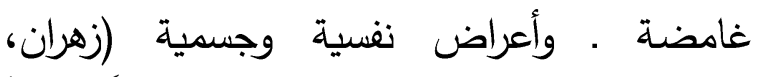

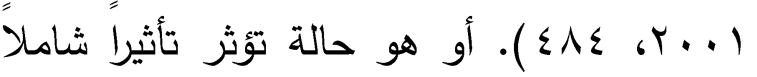
ومستمرا نتيجة وجود تهديد بالخطر ، ويصاحبها

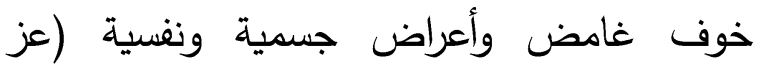

ودراسة (Nezlek, 2002) والتي هدفت

إلى الكثف عن العلاقات اليومية بين الوعي

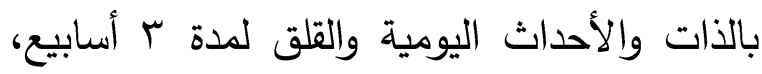
حيث قدم إع مشاركا واقع حالتهم الخاصة والعامة على الوعي الذاتي، والقلق، ولقات وصفوا الأحداث التي وقعت كل يوم. وأثشارت النتائج إلى وجود علاقة ارتباطية بين الأحداث اليومية والقلق اليومي بمستوى الوعي.

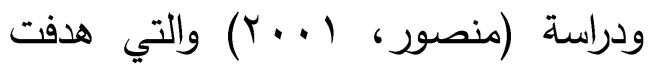

إلى الكثف عن التفاعل بين المكونات العاملية للوعي وعلاقته بالذكاء وبعض العمليات المعرفية على عينة من طلاب الجامعة من قسم علم ولماه النفس - جامعة طنطا. وأشارت النتائج إلى ووجود من لعن وعي عام بالعلاقات المتغيرة والجديدة داخليا وخارجيا، وكذلك وعي بالواقع. ويوجد تفاعل بين

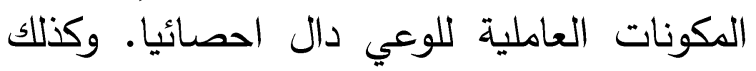
يوجد تفاعل بين المكونات العاملية للوعي وبعض دلف العضات

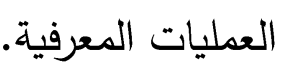
ودراسة (هاشم، ع99 199) والتي هدفت إلى الكثف عن العلاقة بين الوعي بالذات وعلاقته بالقلق المدرسي لدى طلاب المرحلة الثانوية

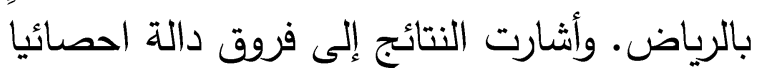
بين طلاب القسم العلمي عن طلاب القسم الأدبي من حيث مستوى القلق لصالح طلاب القسم الأدبي. ولم توجد فرق بين طلاب القسمين من حيث مستوى الوعي. كما وجد علاقة ارتباطية دالة بين مستوى الوعي والقلق المدرسي لاى أفراد

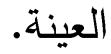


وحيث أن طالب الجامعة ما زال في

مرحلة المراهقة المتأخرة فإنه يعاني من العديد من الصراعات الداخلية التي يمكن أن تكون مصدرا

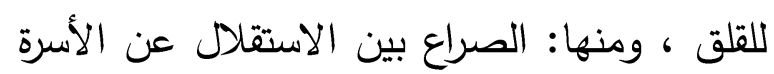

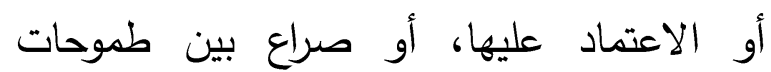
المراهق الزائدة وبين تقصيره الواضح في التزاماته، وصراعه الثقافي بين جيله الذي يعيش فيه بما له له

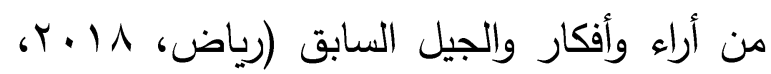
. (YAV

والقلق يمكن أن يكون رد فعل طبيعي لأساليب المعاملة الوالدية أو أساليب التعليم والمتابعة في العملية التعليمية، ولكن يعد مؤشرا خطيراً، حيث يمكن أن يكون هو المدخل للعديد

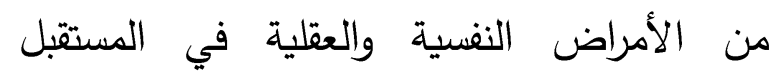

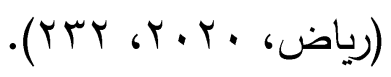

ومن الدراسات التي تتاولت موضوع القلق،

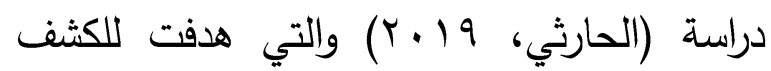
عن العلاقة بين اليقظة العقلية والقلق لاى طلاب

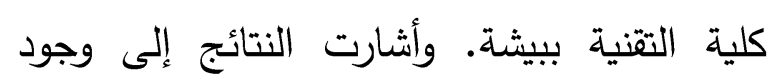
علاقة سلبية دالة احصائياً بين اليقظة العقلية

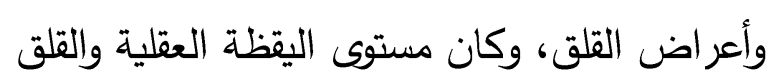
لديهم متوسطة، ووجد فروق دالة احصائيا بين

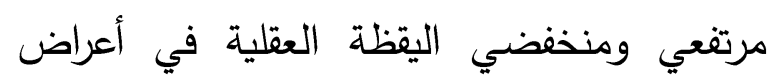
القلق لصالح منخفضي اليقظة العقلية.

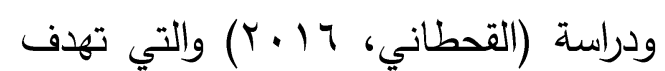
إلى الكثف عن العلاقة بين قلق المستقبل والأفكار غير العقلانية لاى طلاب وطالبات قسم لعن لعن

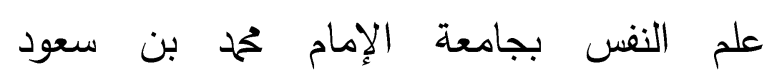
الإسلامية. وأشارت النتائج إلى وجود علاقلة

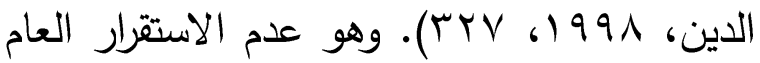
نتيجة الضغوط النفسية الذي تقع على عاتق الفرد مما تسبب الاضطراب في السلوك ويصاحبه

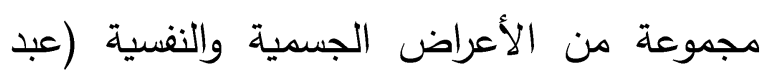

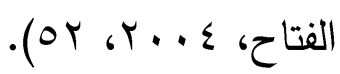

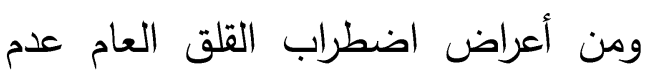

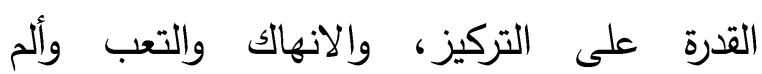
العضلات والأرق وصعوبة في التنفس وجفاف في ولاكي ولاكي الحلق والدوخة والغثيان والعرق المتزيد (فايد، وصنا،

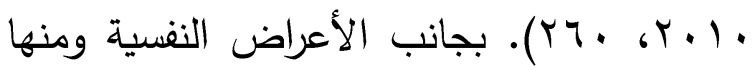
سهولة الاستثارة والثعور بعدم الاستقرار والعصبية

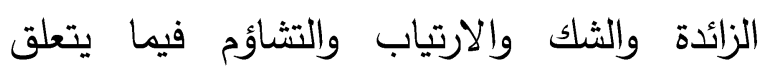

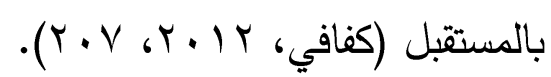
ويوجد للقلق ثلاثة مظاهر وهي الجسدية والمتمثلة في تسارع دقات القلب وتوتر العضلات والتعرق. وانفعالية والمتمثلة في الخوف من فقدان السيطرة على النفس أو الخوف من الموت، فئل وسلوكية والمتمثلة في تجنب المواقف المحرجة

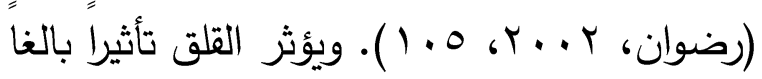

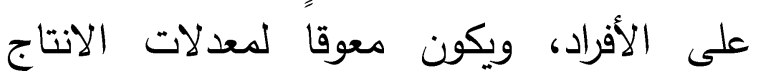

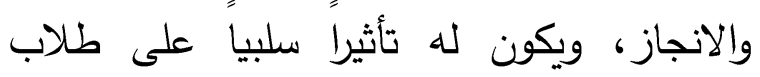
الجامعة من حيث مستوى التحصيل والتكيف الأكاديمي (Uludag, 2014, P.504). وما يميز الأفراد الذين يشخصون

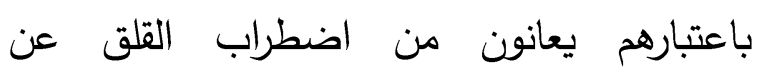

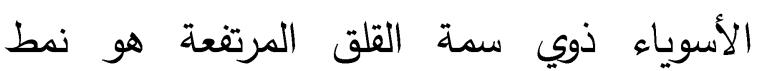
المعلومات التي تئدي إلى تقدير التئ التهديد .(Dagleish,1994, p.154) 
بالنسبة له والقبول بالواقع والعمل على احتمالات

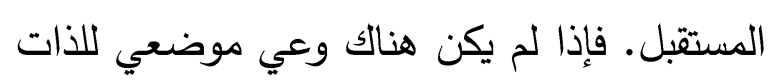

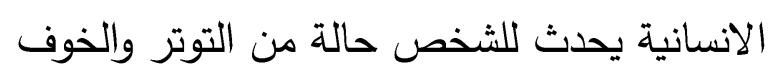
مما يؤثر ذلك على سلوكه وتفكيره وانفعاله، وهذا ما يسمي القلق. وبالرغم من كون القلق خبرة غير

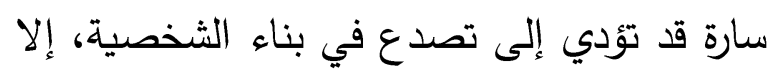
أن وجوده بحدود معينة يعد ضرورة للتكامل النفسي للفرد فهو يخدم أهدافاً هامة في حياة الفرد أو يمكن أن يكون دافعاً للعديد من المهام. وأشارت نتائج الدراسات إلى أن طلاب دن دن الجامعة يتمتعوا بدرجة من الوعي بالذات. مع وجود علاقة ارتباطية دالة ايجابيا بين الوعي بالذات والتوافق النفسي. وكذلك علاقة ارتباطية دالة احصائياً بين الوعي بالذات وقبول الذات

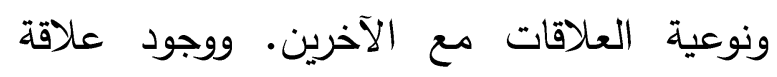
ارتباطية دالة بين مستوى الوعي بالذات والقلق

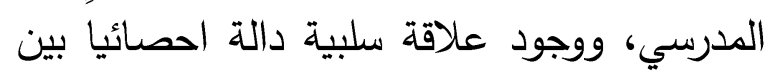
اليقظة العقلية وأعراض القلق، ووجود علاقة ارتباطية دالة موجبة بين الأفكار غير العقلانية وقلق المستقبل. ولم توجد علاقة ارتباطية بين الوعي بالذات وقلق الكينونة. ووجود فروق ثقافية في ادراك الغرد لمراكز التحكم في دوافع الانجاز وعلاقته بالقلق وفقا لاختلاف الوسط. ورجود علاقة ارتباطية بين الأحداث اليومية والقلق اليومي بمستوى الوعي بالذات. ومن خلال هذا الاطار النظري والدراسات السابقة يتضح أن متغيري الوعي بالذات والقلق

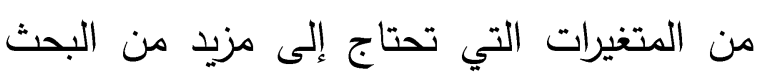

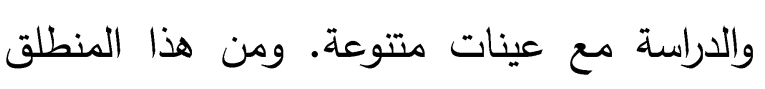

ارتباطية دالة موجبة بين الأفكار غير العقلانية وقلق المستقبل. ووجد فروق دالة إحصائياً بين العينات طبقا للنوع والمستوى الدراسي في كل من القلق والأفكار غير العقلانية. ودراسة (البديري، ع ا • ب) والتي هدفت لقياس الوعي بالذات وقلق الكينونة لدى طلبة الجامعة، وأشارت النتائج إلى أن هنالك فروق في

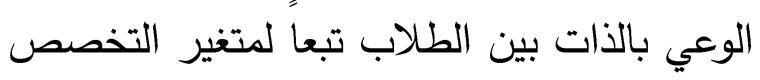

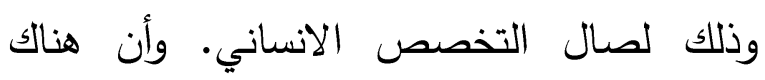
فروق في قلق الكينونة تبعاً لمتغير الجنس وذلك الك لصالح الاناث. ولم توجد علاقة ارتباطية بين الوعي بالذات وقلق الكينونة. ودراسة (الضبع، ج^ه 1 ) والتي هدفت إلى الكثف عن العلاقة بين القلق وادارك الفرد لمركز التحكم في دوافع الانجاز لاى طلاب الجامعة. وأشارت النتائج إلى القلق يرتبط ارتباطا وثيقاً بادراك الفرد لمركز التحكم في دافع الانجاز، وأثارت أيضاً إلى وجود فروق ثقافية في ادراك الفرد لمراكز التحكم في دوافع الانجاز وعلاقته وجودئه بالقلق وفقا لاختلاف الوسط. والقلق يمكن أن يكون اضطراباً سلوكيا أو عرضاً من أعراض بعض الأمراض النفسية، أو

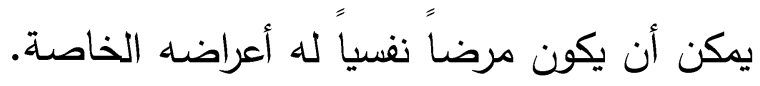
ولذا فالقلق يوجد له في التراث النفسي العديد من لن الدراسات لما له من تأثير فعال في الكثير من فن المتغيرات الأخرى.

تعقيب على الاطار النظري والدراسات السابقة: الوعي بالذات يتضمن معرفة الفرد لنقاط قوته وضعفه، وكذلك المواقف التي تمثل التحدي 
كانت مشكلة البحث الحالي والمتمثلة في تحديد ودراسته الميدانية ثم تقسيرها والوقوف عند مستوى الوعي بالذات والقلق عند طلاب قسم علم مؤشراتها. النفس. وبناء على هذه المشكلة تم صياغة عينة البحثوحدوده:

تحددت عينة البحث من (9) (9البا فروض البحث.

بقسم علم النفس جامعة الطائف تتراوح أعمارهم

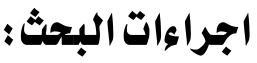

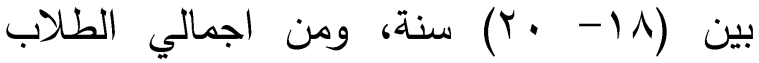

تثمل إجراءات البحث على الفروض،

بالقسم (ع 9) في الفترة الزمنية بين شهري (Y- (Y) والمنهج، والعينة، والأدوات، والأساليب الإحصائية $\cdot r \cdot r \cdot /(r$ المستخدمة. وفيما يلي عرض لهذه الاجراءات. الأدوات: الفروض:

لتفسير فروض الدراسة استخدم الباحث

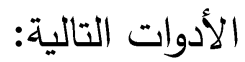

مقياس الوعي بالذات، إعداد: الباحث. - مستوى الوعي بالذات لدى عينة من طلاب قسم علم النفس بجامعة الطائف أعلى من المستوى المتوسط. مقياس ت تايلور J.A. Taylor للقلق الصريح: ترجمة وتقنين مصطفي فهمي، جامعة عين شمس. وحمح أحمد غالي، جامعة الأزهر - أمعاه

أولا : مقيـاس الوعي بـالذات. اعداد الباحث. بعد الرجوع إلى التراث السيكولوجي والدراسات السابقة الخاصة بمتغير الوعي بالذات قام الباحث بتحديد الخصائص الفرعية الخاصة بالوعي بالذات ومن خلال احصاء تكرار وأهمية كل خاصية تم تبياغة عبارات المقياس ومراجعتها لتلأئ العينة المستهدفة. وأصبح المقياس في صورته النهائية يشتمل على (Y^)

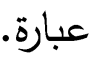

طريقة تصحيح المقياس: يتم الاختيار بين أربع خيارات، والتصحيح على النحو التالي: - مستوى القلق لدى عينة من طلاب قسم علم النفس بجامعة الطائف أعلى من المستوى من المتوسط. - ل ل يوجد فروق دالة احصائيا في درجة الوعي بالذات وفي درجة القلق بين طلاب المستوى

$$
\text { الثاني وطلاب المستوى الرابع. }
$$
- لا توجد علاقة ارتباطية دالة احصائيا بين الوعي بالذات والقلق للى طلاب قسم علم النفس بجامعة الطائف.

منهج البحث: - من

البحث الحالي يهدف إلى قياس الوعي بالذات والقلق لدى عينة من طلاب قسم علم النفس بجامعة الطائف. وهذا يقتضي اعتماد المنهج الوصفي التحليلي لوصف متغيرات البحث وتحليل النتائج التي سيتوصل إليها الباحث من العبارة (Y-1) يكون بناء على نوعية 
عبارة على (V) من الأساتذة المتخصصين في مجال علم النفس والصحة النفسية. وبعد الاطلاع على الملاحظات اللغوية والأدائية للمحكمين وضبط ما اتفق عليه. واستقر المقياس في صورته النهائية على (^^) عبارة دون تغيير

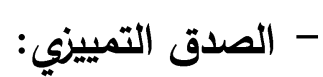

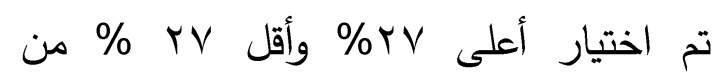
اجمالي عينة التقنين وهي (.9) وتم حساب الم الصدق التمييزي. وكانت النتائج كما في

$$
\text { جدول }
$$

الاختيار. ففي حالة الاختيار (دائما) يحصل على درجات. والاختيار (أحيانا) يحصل على الاحس درجات. والاختيار (نادر) يحصل على درجتين. والاختيار (أبدا) يحصل على لدرجة ورجة واحدة.

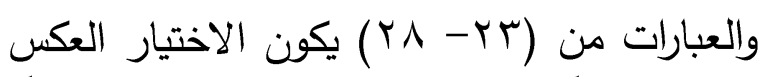
حيث (دائماً) يحصل على درجة واحدة، و(أبداً) على ع درجات. - صدق المقياس: للتحقق من صدق المقياس استخدم الباحث طريقتين لحساب صدق مقياس الوعي بالذات، وهما صدق المحكمين والصدق التمييزي، وذلك على النحو التالي: - صدق المحكمين: قام الباحث بعرض المقياس ودئ في صورته الأولية، والذى تكون من (Y^) جدول الصدق التمييزي لمقياس الوعي بالذات.

\begin{tabular}{|c|c|c|c|c|c|c|}
\hline الدلالة & قيمة ف & قيمة ت & الانحراف المعياري & المتوسط & 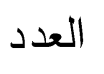 & المجموعة \\
\hline$\cdots 1$ & $r \varepsilon . \varepsilon$ &.$\leqslant 9.17$ &..$Y_{7}$ & r.r & ro & 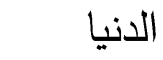 \\
\hline & & &.$\mu_{\Lambda}$ & r.乏) & ro & العليا \\
\hline
\end{tabular}

وأشارت النتائج كما في جدول إلى دلالة ما يعني صدق المقياس في التمييز بين أفراد قيمة ت وقيمة ف بين المجموعة الدنيا والمجموعة العينة في درجة الوعي بالذات.

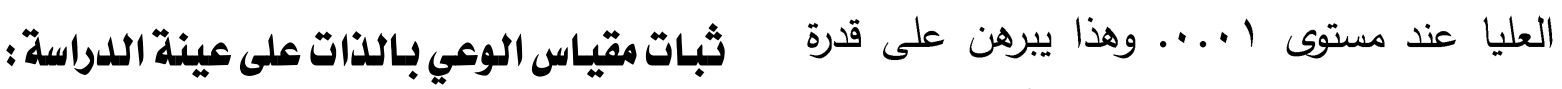
قام الباحث بحساب ثبات مقياس الوعي

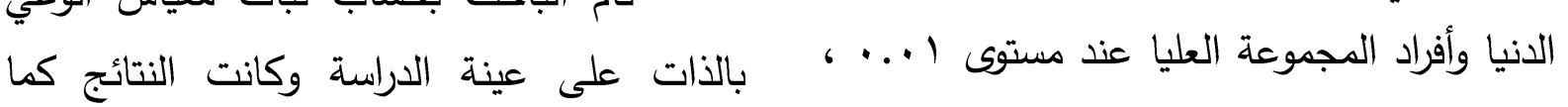
المقياس في التباين والتميز بين أفراد المجموعة يوضحها جدول r. جدول r معاملات ثبات مقياس الوعي الذات، العينة (•).

\begin{tabular}{|c|c|c|c|}
\hline مستوى الدلالة & معامل الثبات & الطريقة & المقياس \\
\hline$\cdots 1$ & $\cdot . \Lambda V$ & سبيرمان براون & الوعي بالذات \\
\hline$\ldots 1$ &. .19 & معامل ألفا- كرونباخ & \\
\hline
\end{tabular}


أحياناً) تحصل على درجة واحدة. (يحدث غالباً)

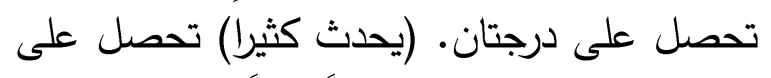

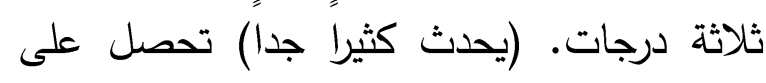
أربعة درجات.

صدق مقياس القلق بعد التعديل: للتحقق

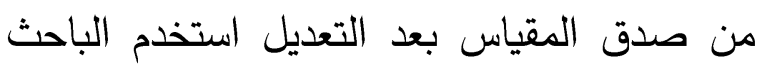

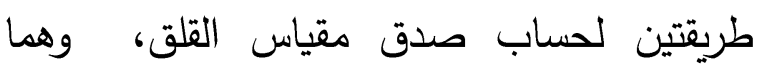

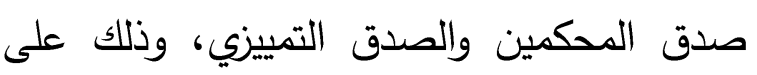

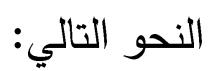
- صدق المحكمين: قام الباحث بعرض المقياس

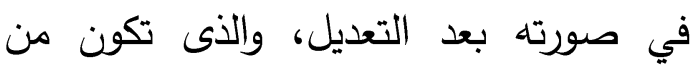

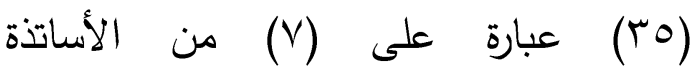
المتخصصين في مجال علم النفس والصحة من الأساتة

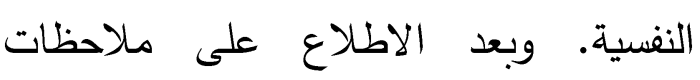
المحكمين وضبط ما اتقق عليه. واستقر المقياس في صورته النهائية على (ب0)

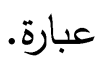

- الصدق التمييزي:

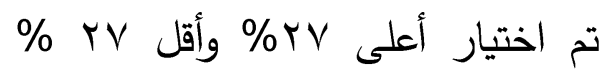
من اجمالي عينة التقنين وهي (·و) وتم حساب التماب

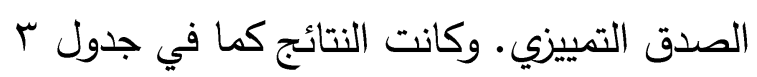

يعرض جدول ب معاملات الثبات سواء بطريقة التجزئة النصفية أو باستخدام معادلة ألفا

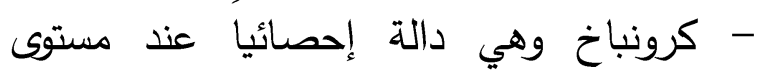
ا...، وهذا يشير إلى الثبات الداخلي لدقياس المسايرة - المغايرة على عينة الدراسة.

\section{ثانياً : مقياس القلق.}

اقتبس اختبار "تايلور" للقلق الظاهر كل معلى

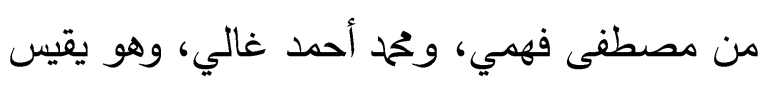

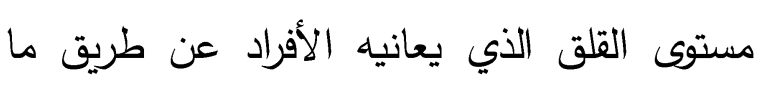
يشعرون به من أعراض ظاهرة وصريحة، وهو

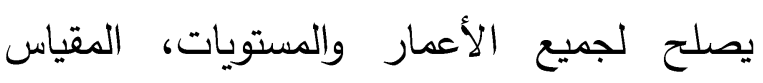
مأخوذ ومترجم عن قياس القلق الصريح ، والذي قامت بتقنينه جانيت تايلور (J.A. Taylor). والمقياس مقتبس من مقياس منيسوتا للشخصية

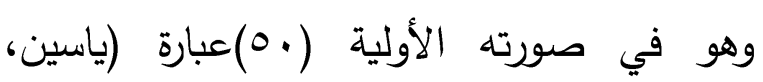

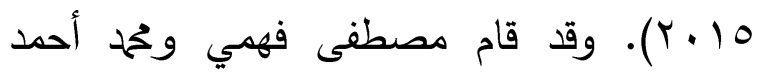
غالي بترجمة المقياس، وإعداده وتتنينه في صورته العربية. والمقياس في صورته النهائية (ب0)

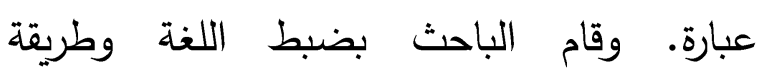
التصحيح، ومن ثم قام بإعادة تقنين المقياس على لصن

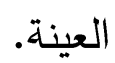

طريقة تصحيح المقياس: يتم الاختيار

بين خمس خيارات، والتصحيح على النحو التالي:

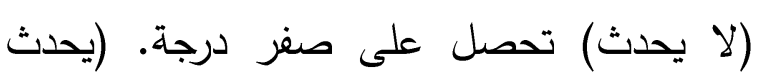

جدولب الصدق التمبيزي لمقياس القلق.

\begin{tabular}{ccccccc}
\hline الدمجوعة \\
\hline
\end{tabular}


وأشارت النتائج كما في جدول ب إلى دلالة المقياس في التمييز بين أفراد العينة في درجة قيمة ت وقيمة ف بين المجموعة الدنيا والمجموعة القلق. العليا. وهذا يبرهن على قدرة المقياس في التباين ثبات مقياس القلق على التهل العينة: قام الباحث بحساب ثبات المقياس على على عينة والتميز بين أفراد المجموعة الدنيا وأفراد المجموعة

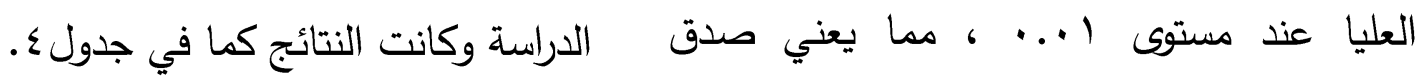
جدول ؛ معاملات ثبات مقياس القلق، العينة (•؟).

\begin{tabular}{|c|c|c|c|}
\hline مستوى الدلالة & معامل الثبات & 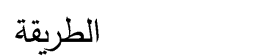 & المقياس \\
\hline$\ldots 1$ &. .10 & سبيرمان براون & أساليب مواجهة الضغوط. \\
\hline$\ldots 1$ &. .AV & عامل ألفا- كرونباخ & \\
\hline
\end{tabular}

يعرض جدولء معاملات الثبات سواء النتائج وتفسيرها:

الفرض الأول والذي ينص على أن:

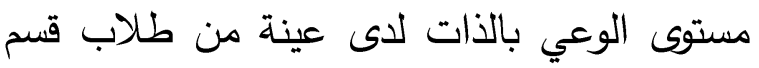

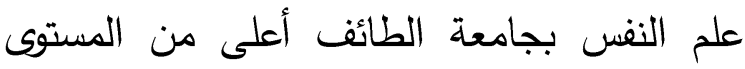
المتوسط.

وللتحقق من هذا الفرض تم حساب

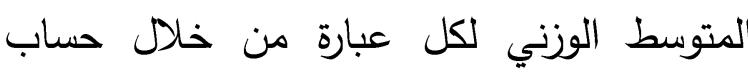

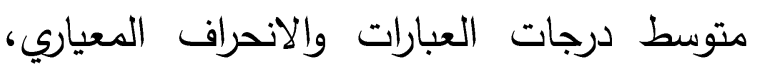

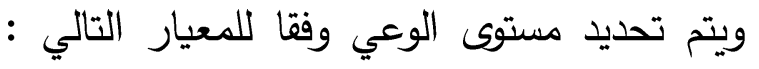
من (Y-1) مستوى منخفض. ومن (Y-Y (Y-Y) مستوى متوسط. ومن (Y- (§) مستوى مرتفع.

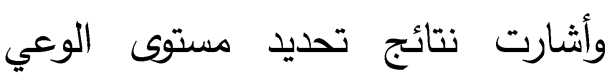
بالذات على عبارات مقياس الوعي بالذات كما

$$
\text { يوضحها جدوله. }
$$

بطريقة التجزئة النصفية أم باستخدام معادلة ألفا كرونباخ، وهي دالة إحصائيا عند مستوى ل ل.... وهذا يشير إلى الثبات الداخلي لـقياس أساليب مواجهة الضغوط على عينة الدراسة. الأسلوب الاحصائي المستخدم: استخدم الباحث برنامج SPSS في تحليل البيانات معتمدا على الأساليب التالية: - مeliability . معل coefficient The correlation - معاملات الارتباط. coefficient - اختبار ت للعينات المستقلة. T.Test

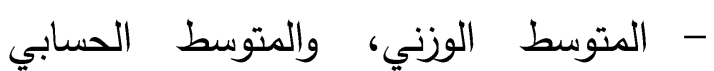

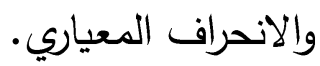

جدوله مستوى عبارات مقياس الوعي بالذات على عينة الدراسة (9)

\begin{tabular}{|c|c|c|c|c|}
\hline 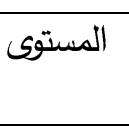 & الالانحراف & الحسابي & العبارة & م \\
\hline 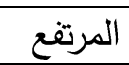 & .01 & $r . \mu r$ & أعرف الأسباب التي تؤدي إلى غضبي. & 1 \\
\hline 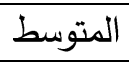 &. .71 & $T .74$ & أحدد مشاعري المسؤولة عن تصرفاتي. & r \\
\hline المرتفع &. .01 & $r .17$ & أققر انفعالاتي وعواطفي تقديرا دقيقا. & $r$ \\
\hline 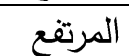 & . . $\leqslant 0$ & $r .17$ & أعى ما أقوم به من أعمال يومية. & $\varepsilon$ \\
\hline 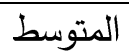 & 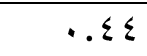 & T.AT & استطيع أن أحدد نقاط قوتي ونقاط ضعفي. & 0 \\
\hline
\end{tabular}




\begin{tabular}{|c|c|c|c|c|}
\hline المرتقع & .04 & T.乏V & أعرف الأسلوب الذي يعمل به عقلي. & 7 \\
\hline المرتقع & $\cdot . \leqslant \varepsilon$ & $r .17$ & أعرف قدراتي وأوجهها لتحقيق أهدافي. & v \\
\hline المرتفع &..$\mu \Lambda$ & T.乏૫ & أعرف بالضبط ماذا أريد أن أفعل. & $\Lambda$ \\
\hline المتوسط &. .79 & T.77 & أشعر بحالة من الارتياح عندما أتحدث لنفسي. & 9 \\
\hline المرتفع & .10 & $r . \leqslant 9$ & أتمكن من تحديد أخطائي. & 1. \\
\hline المرتفع &. .90 & T.乏A & أشعر بالثقة في نفسي. & 11 \\
\hline المرتفع &.$\wedge 7$ & r.r & أتمكن من ايجاد حلول لمشكلاتي الخاصة. & ir \\
\hline المرتفع &..$\wedge r$ & 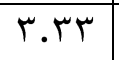 & أهتم بأسلوبي الخاص في عمل الأثياء التي أقوم بها. & $\pi$ \\
\hline المتوسط &..$\times 1$ & T.77 & أستطيع التعامل مع المواقف غير المتوقعة. & $1 \varepsilon$ \\
\hline المرتفع &. .71 & $r .17$ & أقدر أسوء العقبات قبل الشروع في أي عمل مع زملائي. & 10 \\
\hline المتوسط &. .70 & r.99 & أسعى إلى تحقيق أهدافي الاجتماعية بأي وسيلة. & 17 \\
\hline المرتقع &. $.9 \varepsilon$ & r.r. & أحاول التغلب على الظروف الاجتماعية التي تعيق طموحاتي. & iv \\
\hline المرتفع & $\cdot . \wedge r$ & $r .17$ & أتمكن من تحديد ما يفكر به الآخرين. & 11 \\
\hline المتوسط &.$V \varepsilon$ & t.rT & اعرف أنني مؤهلا لعمل أعمال متميزة. & 19 \\
\hline المتوسط &. $.7 \wedge$ & T.70 & أتحكم في انفعالاتي بسهولة. & r. \\
\hline المتوسط &..$\vee 9$ & T.Tะ & أعرف كيف أتعامل مع الآخرين. & Y) \\
\hline المتوسط &. .00 & tr.tr & يمكن بمهاراتي التغلب على كل المعوقات. & YY \\
\hline المتوسط &. & T.17 & أخاف من المهام الجديدة. & rt \\
\hline المتوسط &.. $\mathrm{r}$ & T.M & تتقصني الثجاعة في نقد سلوكياتي. & $r \varepsilon$ \\
\hline المتوسط &.$\leqslant 1$ & T.Y & أشعر بالحرج عندما أكون مع أشخاص أجهل معرفتهم. & ro \\
\hline المتوسط &..$M$ & T.TV & أتزدد في المبادرة بالقيام بأي نشاط جماعي. & r7 \\
\hline المرتقع &..$\leqslant 0$ & $r .11$ & أعتقد أن أفكاري محدودة في تعاملي مع مشكلات الحياة. & rV \\
\hline المتوسط & $.7 \varepsilon$ & T.71 & عندما أشعر بالانزعاج فإنني أجهل سببه. & rᄉ \\
\hline
\end{tabular}

يتضح من خلال جدوله أن مستوى هناك علاقة ارتباطية دالة احصائيا بين الوعي

الوعي بالذات لاى العينة يتراوح بين المستوى بالذات وقبول الذات. ويمكن أن يرجع الوعي بالذات إلى طبيعة المتوسط والمستوى المرتفع. وهذا يعني أن طلاب العينة لديهم درجة من الوعي بالذات. والذى المقررات التي تدرس في قسم علم النفس أو ترجع يتضمن معرفة نقاط القوة والضعف كما أشار إلى الخبرات الحياتية. ولكن ليست بدرجات مرتفعة (Hippe, 2004, p. 241) وهذا يتفق مع دراسة في كل المجالات. فمن العبارات المرتفعة: أعرف

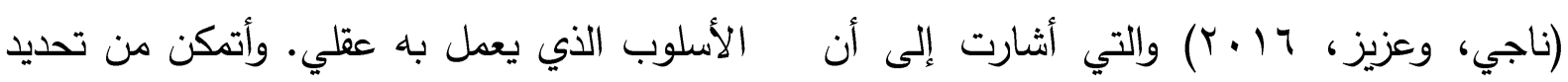
طلاب الجامعة يتمتعوا بالوعي الذاتي. ودراسة أخطائي. وأشعر بالثقة في نفسي. ومن العبارات

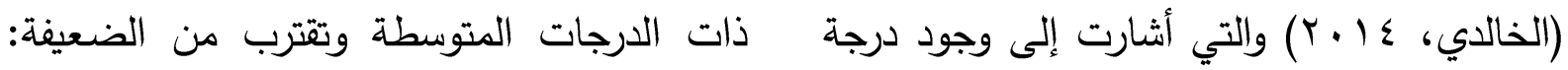
من الوعي الذاتي لدى طلاب المرحلة الثانوية. أخاف من المهام الجديدة. وأشعر بالحرج عندما ودراسة (Fung, 2011) والتي أشارت إلى أن أكون مع أشخاص أجهل معرفتهم. ويمكن بمهاراتي التغلب على كل المعوقات. وهنا تحقق 
الفرض بنسبة حيث تراوح مستوى الوعي عند شكل ا توزيع درجات العينة (19) على مقياس الوعي بالذات.

الفرض الثاني والأي ينص على أن: مستوى لم: لم: طلاب قسم علم النفس بين المستوى المتوسط القلق لاى عينة من طلاب قسم علم النفس بجامعة الطائف أعلى من المستوى المتوسط. وللتحقق من هذا الفرض تم حساب المتوسط الوزني لكل عبارة من خلال حساب متوسط درجات العبارات والانحراف المعياري، ويتم تحديد مستوى القلق وفقا للمعيار التالي: من (صفر - مال

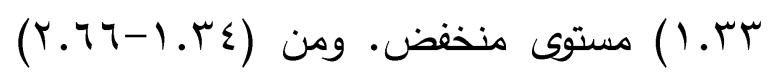
مستوى متوسط. ومن (YV.TV ( - ع ) مستوى مرتفع. وأشارت نتائج تحديد مستوى القلق على عبارات مقياس القلق كما يوضحها جدول 7. والمستوى المرتفع. وشكل ا يوضتح توزيع درجات العينة على مقياس الوعي بالذات حيث قريب من الشكل الاعتدالي، وهذا يعني أنه يوجد شريحة من العينة تستطيع الوعي بالذات بدرجة عالية وتوجد شريحة أخري يوجد لديها قدر من الوعي بالذات، وهذه الشريحة يمكن أن تكون لديها وعي بالذات ضعيف. لكن الشريحة العظمي تقع في درجات الوعي بالذات بالمستوى المتوسط.

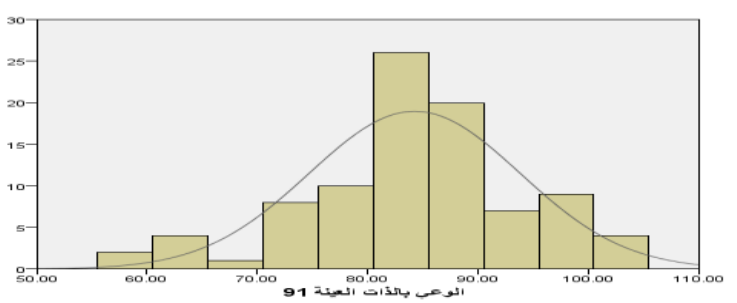

جدول7. مستوى عبارات مقياس التلق على عينة الدراسة (9)

\begin{tabular}{|c|c|c|c|c|}
\hline 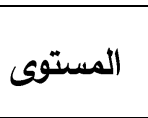 & الالمعراف & الحسابي & 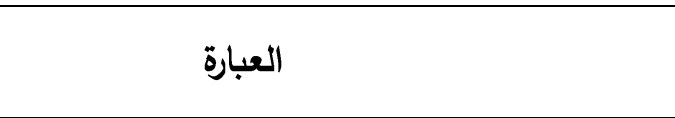 & b \\
\hline المتوسط &..$r q$ & 1.70 & أشعر أنني متوتر . & 1 \\
\hline المتوسط & 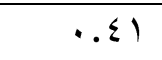 & $1.7 \varepsilon$ & ينتابني شعور بأن شيئًا فظيعا قد يحدث. & $r$ \\
\hline المتوسط & $\cdot . \leqslant 1$ & 1.17 & أحس بالخوف لارجة أن أوجاعا تتتابني في البطن. & r \\
\hline المنخفض &..$\leqslant 0$ &. $.0 Y$ & 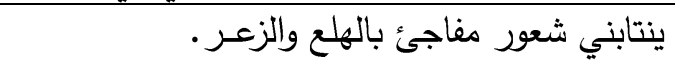 & $\varepsilon$ \\
\hline المنخفض &.$r \varepsilon$ & $1.1 \mathrm{~V}$ & نومي قلق ومتتطع. & 0 \\
\hline المتوسط & $.0 r$ & $1.0 Y$ & لدي مخاوف أكثر من غيري. & 7 \\
\hline 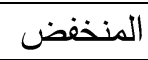 & $\cdot . \leqslant \varepsilon$ &.$\mu \Lambda$ & أحلم أحلاما مزعجة أثناء النوم. & V \\
\hline المنخفض &.. $\mathrm{r} \Lambda$ & $.7 \mathrm{~V}$ & لا أستطيع الانتباه لحاجة واحدة فقط بسهولة. & $\wedge$ \\
\hline
\end{tabular}




\begin{tabular}{|c|c|c|c|c|}
\hline المنخفض & $\cdot . \leqslant 9$ & $1, r r$ & أشعر بالانقباض والضيق. & 9 \\
\hline المتوسط & . & $1 . r 0$ & أشعر بالتعب. & 1. \\
\hline المتوسط &. & $1.0 r$ & الانتظار يجعلني عصبيا. & 11 \\
\hline المتوسط & . & $1.0 Y$ & أكون قلقا لدرجة أنني لا أستطيع أن أستقر في مكان واحد. & IY \\
\hline 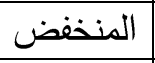 &. .rt & $1.1 \mathrm{~V}$ & 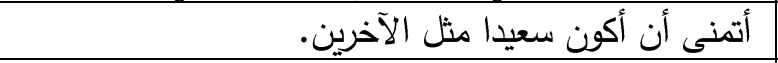 & 14 \\
\hline 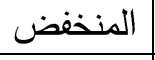 &. .71 & $\cdot . \wedge r$ & لا أستطيع التركيز لوقت طويل. & $1 \leqslant$ \\
\hline المنخفض &.$\mu_{1}^{\prime}$ & $.9 \mathrm{~V}$ & أشعر بأنني غضبان ومتوتر . & 10 \\
\hline المنخفض &..$\leqslant 0$ &. .71 & أعرق كثيرا وبسهولة حتى أيام البرد. & 17 \\
\hline المتوسط &. $\mathrm{TH}$ & $1 . \varepsilon \wedge$ & الحياة بالنسبة لي تعب ومضايقة. & IV \\
\hline المنخفض &..$\leqslant 1$ & $.7 \mathrm{~V}$ & أخاف من شيء مجهول وأخشى أن يحدث لي مكروه. & 11 \\
\hline المنخفض &..$\wedge 1$ & $.0 \leqslant$ & أشعر بالخجل من نفسي. & 19 \\
\hline المتوسط &..$\leqslant 0$ & $1 . r 0$ & أشعر بزيادة ضربات وضيق في التتفس. & $r$. \\
\hline المتوسط &.$r \varepsilon$ & 1.70 & أخاف من أشياء لا تستحق الخوف. & rI \\
\hline المتوسط &.$\mu^{\mu}$ & 1.04 & ينتابني الصداع كثيرا. & rt \\
\hline المنخفض & $\cdot . \Sigma 1$ & $1.1 \mathrm{r}$ & أرتبك بسهولة حينما أقوم بعمل ما. & r \\
\hline المنخفض &.$\mu^{\mu}$ & $1.1 \mathrm{~V}$ & أنا حساس أكثر من غيري. & $r \varepsilon$ \\
\hline المنخفض &.$\leqslant 0$ & $.0 Y$ & دائما أشعر بالدفء في الأيادي والأرجل. & ro \\
\hline المنخفض & $.7 \varepsilon$ & $.0 Y$ & أتضايق أثناء أدائي لأي عمل ما. & rt \\
\hline المنخفض &. $\mathrm{Vr}$ & 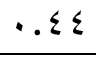 & ليس للدي ثقة في نفسي. & rV \\
\hline المنخفض & $\because Y \leq$ & $\because \leqslant 1$ & أصاب بحالات إمساك تضايقني. & YA \\
\hline المتوسط &.$\mu \Lambda$ & $1.7 \mathrm{~V}$ & أشعر بأنني مشغول البال ومهموم. & rq \\
\hline 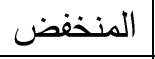 & $\cdot . \leqslant 9$ & 1.11 & للدي إحساس بالعصبية والاستتارة. & $r$. \\
\hline 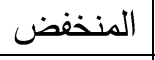 &. ro & 1.11 & أشعر بتراكم المصاعب علي من كل ناحية. & M \\
\hline المتوسط & .ro & $1 . r \varepsilon$ & أقلق بشأن أمور بسيطة. & rr \\
\hline المتوسط &. $\mathrm{rr}$ & 1.07 & 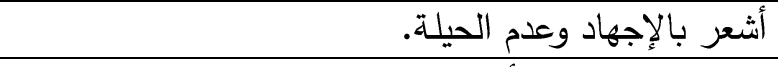 & r \\
\hline 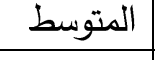 & $\cdot . \Sigma 1$ & $1 . \wedge r$ & يدق قلبي وترتعش أطرافي عندما تكون لدي مشكلة. & r乏 \\
\hline المنخفض &.$\mu^{\mu}$ & $.7 \mathrm{~V}$ & أشعر بالغثيان ومشكلات في المعدة. & ro \\
\hline
\end{tabular}

يتضح من جدولج أن مستوى القلق عندباعتبارهم يعانون من اضطراب القلق عن

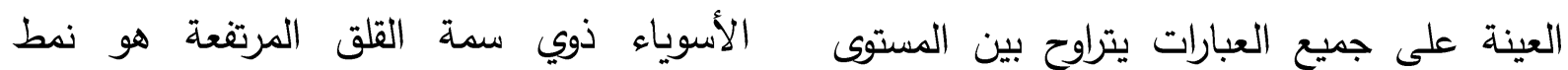
المنخفض والمستوى المتوسط. وهذا يعني المعلومات التي تؤدي إلى تقدير التهديد. الاختلاف بين أفراد العينة يمكن أن يرجع إلى كم (Dagleish,1994, p.154)

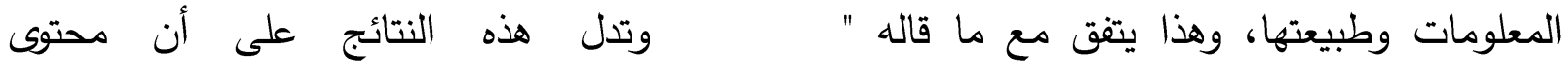
Dagleish 
حالة من القلق بدرجة عالية. وأن من يتسم أخري يوجد لديها درجة متوسطة من القلق وأخرى بدرجات متوسطة ومرتفعة هم من لديهم خبرات قليلة يوجد لديها قلق مرتقع.

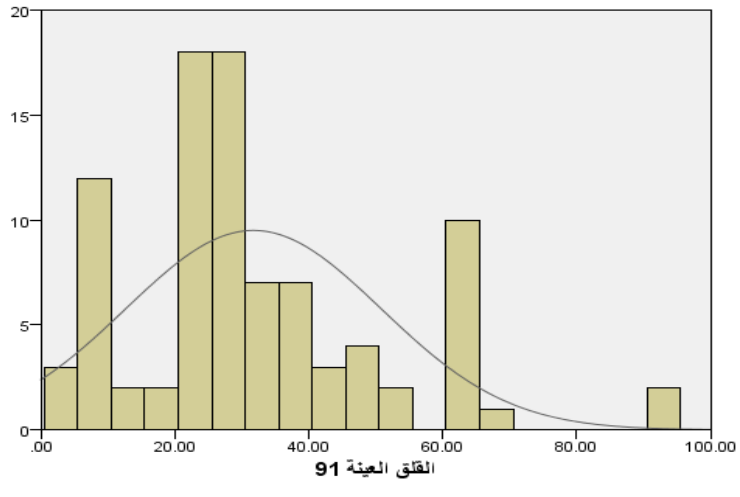

شكل r توزيع درجات العينة (91) على مقياس القلق.

الفرض الثالث والذى ينص على: لا يوجد فروق دالة احصائيا في درجة الوعي بالذات وفي درجة القلق بين طلاب المستوى الثاني وطلاب المستوى الرابع.

وللتحقق من هذا الفرض تم حساب قيمة "ت" بين طلاب المستوين الرابع والثاني على متغيري الوعي بالذات والقلق. والنتائج كما تضح

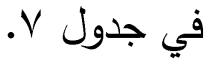

ومعلومات تجعلهم يقدروا الأمور والمواقف على أنها تهديد. ومن العبارات التي تتنمي للمستوى المتوسط: أشعر أنني متوتر • وينتابني شعور بأن شيئا فظيعا قد يحدث. ويدق قلبي وترتعش أطرافي عندما تكون لدي مشكلة. ومن العبارات ذات المستوى المنخفض: ليس لدي ثقة في نفسي. وأحلم أحلاما مزعجة أثناء النـوم. وينتابني شعور مفاجئ بالهلع والزعر • وهنا لم يتحقق الفرض الثاني حيث أن مستويات الطلاب على مقياس القلق كانت بين المنخفض والمتوسط ولم ترتقع عن المستوى

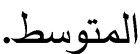
وشكل ب يوضح توزيع درجات العينة على مقياس القلق ملتوى إلى المستوى المنخفض، وهذا يعني أنه يوجد شريحة كبيرة من العينة يوجد عندها درجة منخفضة من القلق وتوجد شريحة

جدول V قيمة اختبار ت للعينات المستقلة على مقياس الوعي بالذات ومقياس القلق.

\begin{tabular}{|c|c|c|c|c|c|c|}
\hline & قيمة ت & الاتحراف المعياري & المتوسط الحسابي & العينة & المستوى الدراسي & المتغير \\
\hline \multirow[t]{2}{*}{ غير دالة } & \multirow[t]{2}{*}{..$A V V$} & $11.0 \varepsilon$ & NY.9T & r & المستوى الرابع & الوعي بالذات \\
\hline & & N.or & $\wedge \varepsilon . \wedge 0$ & $\pi r$ & المستوى الثاني & \\
\hline \multirow[t]{2}{*}{ غير دالة } &. $.0 \vee \wedge$ & $r \cdot . \cdot r$ & rT.so & rq & المستوى الرابع & القلق \\
\hline & & IA.Vr & $r . .9 r$ & $\pi$ & المستوى الثاني & \\
\hline
\end{tabular}


وللتحقق من صحة هذا الفرض قام الباحث

بحساب معامل الارتباط بين أبعاد مقياس الوعي هن

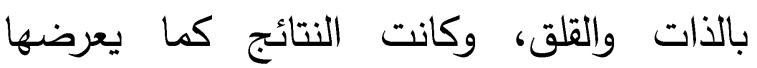
جدول^. جدولم معامل الارتباط بين درجات العينة على مقياس الوعي المقياس بالذات ومقياس القلق.

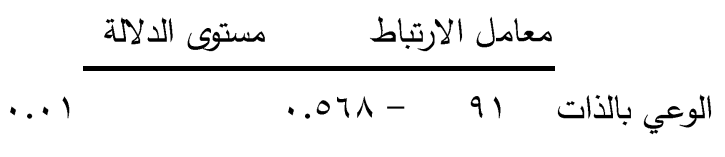

القلق

واتضح من جدولى وجود ارتباط سالب

دال احصائيا عند مستوى ال... بين درجات

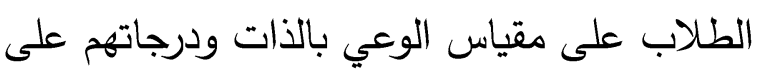

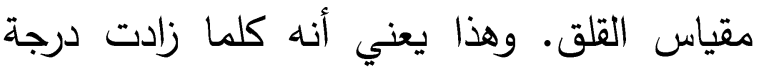
الوعي بالذات انخفضت درجة القلق عند الطلاب. وهذا يتقق مع دراسة (هاشم، ع991) والتي

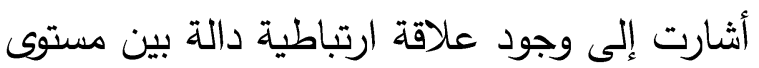
الوعي والقلق المدرسي لدى أفراد العينة، ودراسة

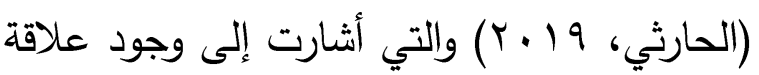
سلبية دالة احصائيا بين اليقظة العقلية وأعراض

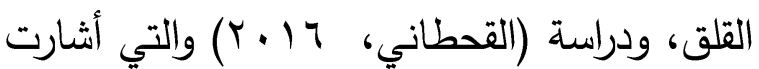
إلى وجود علاقة ارتباطية دالة موجبة بين الأفكار غير العقلانية وقلق المستقبل، ودراسة (البديري،

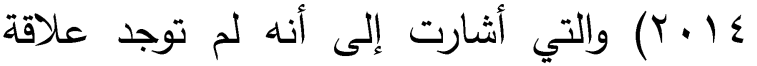
ارتباطية بين الوعي الذاتي وقلق الكينونة. ودراسة (Nezlek, 2002) علاقة ارتباطية بين الأحداث اليومية والقلق اليومي بمستوى الوعي.
يتضح من جدول V أنه لا يوجد فروق ذات دلالة احصائية بين طلاب المستويين الدراسين الثاني والرابع على مقياسي الوعي بالذات والقلق. ويمكن أن يرجع ذلك إلى عدم وجود فروق معرفية كبيرة بين المستويين لقرب المستويين وقلة الفجوة بين المستويين من حيث الخبرات والمعلومات. حيث يقول " الزيات"'": يتوقف المدى المحدد

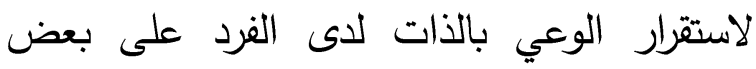
المقومات منها فكرة الفرد المسبقة عن نفسه وعن قدارته ومعلوماته وامكاناته التي يمتلكها. (الزيات،

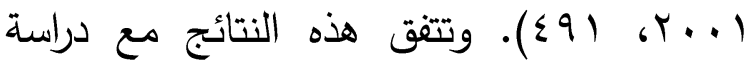

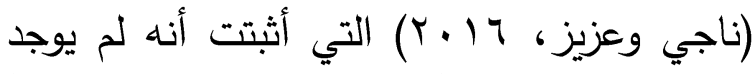
فروق دالة احصائيا بين طلاب الجامعة تبعا لمتغير الجنس والتخصص والمرحلة.

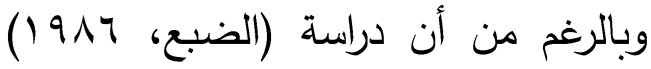
أثارت إلى وجود فروق ثثافية في ادرالك الفرد لمراكز التحكم في دوافع الانجاز وعلاقته بالقلق وفقا لاختلاف الوسط. ولكن لم تتضح هذه الفروق

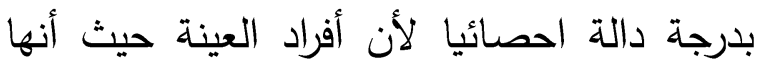
من نفس الوسط الاجتماعي تقريبا، وتتثابه في لنيان

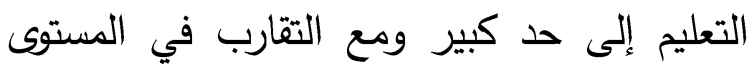
الدراسي مما يجعل الفروق بينهم غير دالة

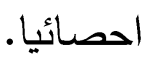

وهنا لم يتحقق الفرض الثالث حيث لم يوجد فروق ذات دلالة احصائية بين طلاب المستويين الثاني والرابع على مقياسي الوعي بالذات والقلق.

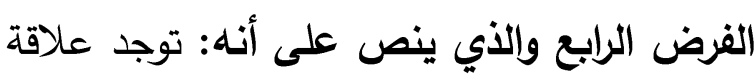

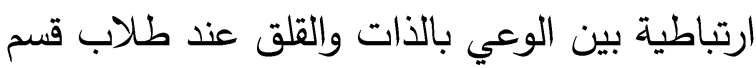
علم النفس بجامعة الطائف؟. 
وهذا يفسر أهمية صفة الوعي بالذات

كمؤشر لصحة نفسية جيدة، حيث تساعد خصائص الوعي بالذات الثخص على فهم نفسه

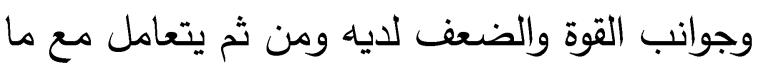
يعترضه من مواقف وتهديدات بأسلوب مناسب، ويمتلك الثقة بالنفس التي تساعده على مقاومة

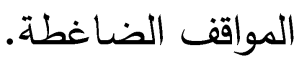

وطلاب علم النفس يقومون بدراسات

تهدف إلى فهم السلوك الانساني وتحليله ولذا

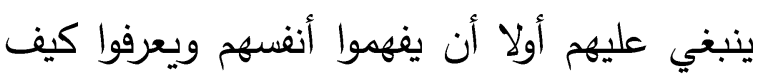

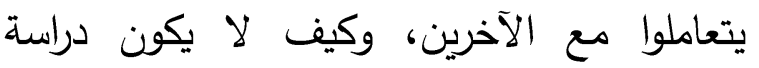

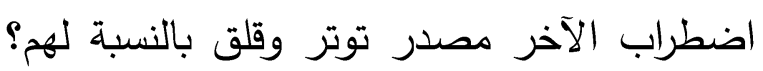
حتى يستطيعوا تقديم العون لمن يحتاج. توصيات البحث:

من خلال نتائج البحث يمكن التوصية بما يلي:

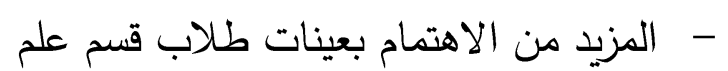
النفس من خلال العديد من المتغيرات التي

$$
\text { تكثف جوانب شخصياتهر. }
$$

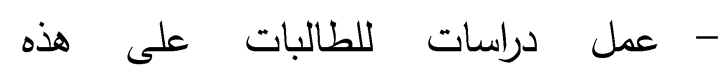

المتغيرات ومقارنة النتائج بالطلبة.

- عمل دراسات مقارنة بين الطلاب في أول الطية

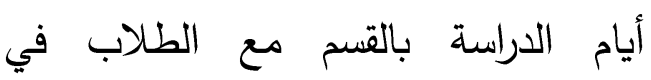
المستوى الدراسي الأخير • حتى يتم تحديد التأثير الفعلي لدراسة مقررات علم النفس لأن

$$
\text { على جوانب الثخصية. }
$$

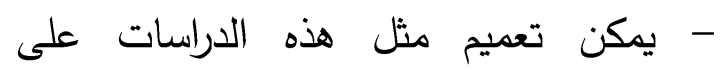
الأقسام العلمية الأخرى لتفسير التغيرات
وهنا تحقق الفرض الرابع حيث يوجد

علاقة ارتباطية بين الوعي الذات والقلق لدى أفراد

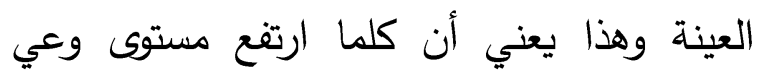
الطالب بذاته وتتمو معارفه ومعلوماته يستطيع أن أن يتحكم في مواطن القلق أو مسبباته.

وشكل بوضح العلاقة الارتباطية السالبة

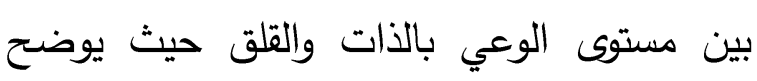

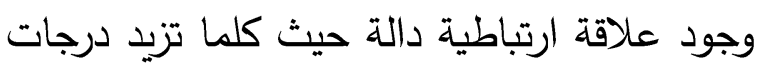

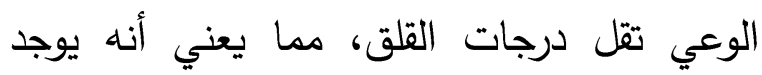
ارتباط دال سالب بين الوعي بالذات والقلق.

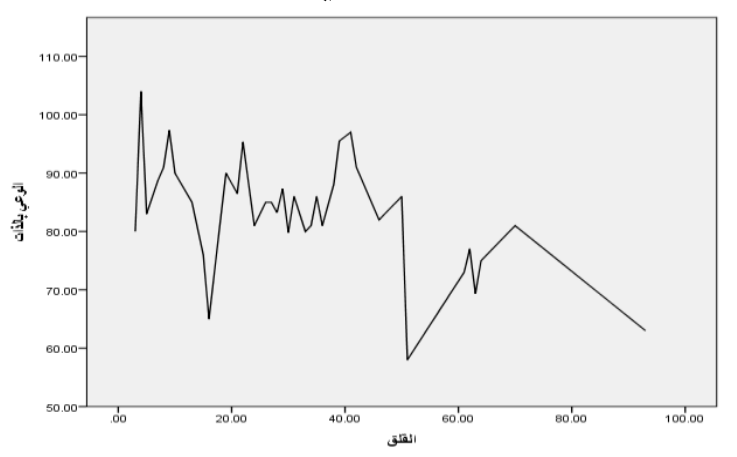

شكل r مستوى الارتباط بين درجات العينة (19) على مقياسي الوعي بالذات والقلق.

\section{تعقيب على النتائج.}

يتضح من خلال نتائج البحث أن مستوى

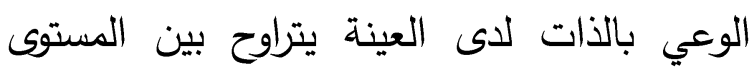

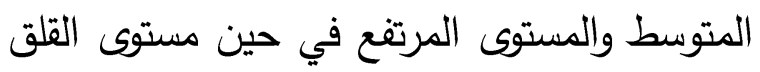
يتراوح بين المستوى المنخفض والمستوى المتوسط. وبالتالي أثبتت النتائج وجود علاقة ارتباطية سلبية بين الوعي بالذات والقلق. ولم تثبت النتائج فروق التباتيه دالة احصائيا بين المستويين الدراسيين الثاني ولئي والرابع في كل من الوعي بالذات والقلق. 
الخالدي، عبد الرحمن (ع ا • (ا). الوعي الذاتي وعلاقته بالتوافق النفسي لدى طلاب

وطالبات المرحلة الثانوية، روسالة

ماجستير في الارشاد التربوي ، جامعة

$$
\text { الملك عبد العزيز، جدة. }
$$

راجح، أحمد عزت (999 1). أصول علم النفس،

$$
\text { طا (، القاهرة، دار المعارف. }
$$

رضوان، سامر جميل (Y ... (Y). الصحة النفسية،

عمان، دار المسيرة للنشر والتوزيع.

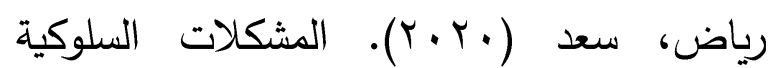

للأطفال والمراهقين، القاهرة، ابداع

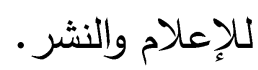

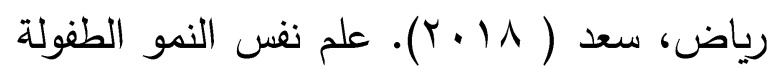
والمراهقة، طب، القاهرة، دار ابن

$$
\text { الجوزي. }
$$

الزبيدي، كامل علوان ( ( . ب). دراسات بين الصحة النفسية، كلية الآداب ، جامعة

بغداد.

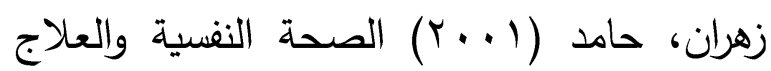
النفسي، طّ، القاهرة، عالم الكتب.

الزيات، فتحي (1 (ب). البنية العاملية للكفاءة الذاتية الأكاديمية ومحدداتها، سلسلة علم النفس المعرفي، مدخل ونماذج ونظريات، (T) ج( Y)، القاهرة، دار

$$
\text { النشر للجامعات. }
$$

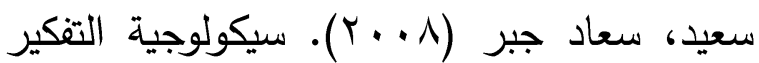
والوعي الذاتي، طا، عمان، عالم

الكتب الحديث للنشر والتوزيع.
السلوكية التي تحدث للطلاب في الجامعة مع ضغوط التخصص وممارسات التعلم. - عمل برامج ارشادية للطلاب ممن أظهرت النتائج لديهم ضعف في مستوى الوعي بالذات وارتقاع في مستوى القلق. - تفعيل الارشاد الطلابي في الجامعة مستندا على نتائج مثل هذه الأبحاث.

\section{المراجع}

\section{المراجع العربية}

أبو النور، حمد وخحم، آمال وخطاطبة، يحي

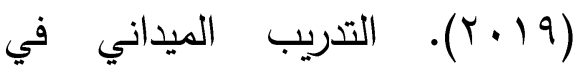
مجالات علم النفس(بين النظرية والتطبيق)، الرياض، دار الزهراء. أبو النور، محم وخطاطبة، يحي وفارح، الوليد (1) نظرية وحالات تطبيقية في ضوء معايير الاليل الاحصائي والتشخيص الخامس، دار الزهراء، الرياض. الببلاوي، فيولا (9Av ( ). مقياس القلق للأطفال، القاهرة، مكتبة الأنجلو المصرية. البديري، هاني (ع ا •r). الوعي الذاتي وعلاقته بقلق الكينونة لدى طلبة الجامعة المستتصرية، رسالة ماجستير ، كلية الآداب، الجامعة المستتصريـة. الحارثي، سعد يحم (19 (r). اليقظة العقلية وعلاقتها بأعراض القلق لدى طلاب الكلية التقنية بمحافظة بيشة، جامعة سوهاج، المجلة التربوية، عدد OV. 


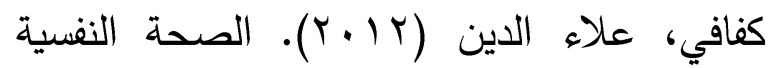
والارشاد النفسي، الرياض، دار النشر

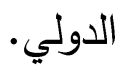

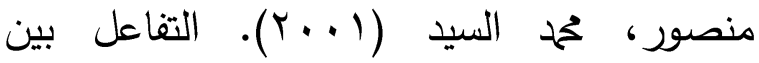
المكونات العاملية للوعي وعلاقته بالذكاء وبعض العمليات المعرفية، رسالة دكتوراة غير منشورة، كلية الآداب ، جامعة طنطا.

ناجي، محود ناجي وعزيز، تقي (T (ب). الوعي الذاتي للى طلبة الجامعة، مجلة كلية التربية الجامعة المستنصرية، العدد ع.

هاشم، سامي حمد (ع99 1). العلاقة بين الوعي بالذات وعلاقته بالقلق المدرسي لدى

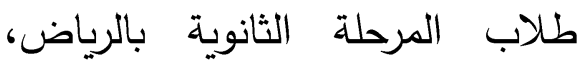
مجلة كلية التربية، الزقازيق، عدد اY ياسين، سهى (10) الكفاءة السيكومترية لمقياس بيك للقلق على عينات من الأسوياء والمرضى النفسيين، رسالة ماجستير ، كلية التربية، جامعة دمشق.

\section{المراجع الأجنبية: - اجية}

Buss, A. (1980). Self Consciousness and Social Anxiety, University of Texas, W, H, Freeman and company.

Dagleish,T.(1994). The appraisal of threat and the process of selective attention in clinical and subclinical anxiety states, Issues clinical psychology and psychotherapy, 1 ,

Fung, C.(2011). Exploring individual selfawareness as it relates to
الضبع ، ثناء يوسف (T^19 ). العلاقة بين القلق وادرالك الفرد لمراكز التحكم والضبط في دوافع الانجاز لدى الطلبة من الجنسين" دراسة عضارية مقارنة، رسالة دكتوراه غير منشورة، كلية البنات جامعة عين شمس.

عبد الفتاح، نيرة (ع . . ץ). مدى فعالية برنامج ارشادي عقلاني انفعالي في تخفيض القلق والاكتئاب والخوف من الموت لاى عينة من الأطفال مرضى القلب، رسالة دكتوراه، معهد الدراسات العليا للطفولة، جامعة عين شمس. القاهرة. عز الدين، عادل (1991). سيكولوجية الشخصية، القاهرة، مكتبة الأنجلو

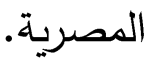

فايد ، حسين (· ( • (ب). علم الأمراض النفسية

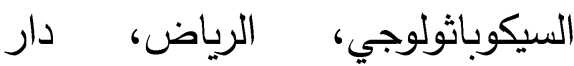

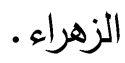

القحطاني، حمد مترك (T) (Y). قلق المستقبل وعلاقته بالأفكار غير العقلانية في ضوء بعض المتغيرات الديموجرافية لدى طلاب وطالبات قسم علم النفس بجامعة الامام محم بن سعود الاسلامية. مجلة العلوم الانسانية والاجتماعية، العدد اء، جامعة الامام حمح بن سعود الإسلامية. كفافي، علاء الدين وسالم، سهير (V . . r). مدخل بـ إلى علم النفس، الرياض، دار النشر

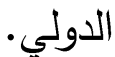


Riskind J., Alloy L. \&Manos M. (2005). Abnormal Psychology; Current Perspectives, (5th ed). New York, MC GrawHill.

Topuza ,C. \&Arasan, Z. (2014). Selfawareness group counseling model for prospective counselors' procedia - Social and Behavioral Sciences, 143.

Uludag, O. (2014). Fair and Square: How does Perceptions of Fairness is Associated to Aggression?. Procedia Social and Behavioral Sciences, 145(3).

Warmerdam, G. (1994). Pathway to happiness (self-awareness) article, Mexico, http://www.Pathway to happiness.com self-acceptance and the quality of interpersonal relation, Unpublished Ph.D. dissertation, Pepperdine University, USA.

Goleman, D. (1995). Emotional intelligence: why it can matter more than IQ. New York, Bantam Books.

Hippe, J. (2004). Self-awareness: a precursor to resiliency, Reclaiming Children and Youth, 2(4).

Jack, K. \& Smith, A. (2007). Promoting self-awareness in nurses to improve nursing practice. Nursing Standard, 21(32).

Nezlek, J. (2002). Day-to-Day Relationships Between Self-Awareness, Daily Events, and Anxiety, Journal of Personality, Blackwell Publishers, USA ,70 (2). 